\title{
Reduced Anterior Corpus Callosum White Matter Integrity is Related to Increased Impulsivity and Reduced Discriminability in Cocaine-Dependent Subjects: Diffusion Tensor Imaging
}

\author{
Frederick Gerard Moeller*,', Khader M Hasan², Joel L Steinberg', Larry A Kramer², Donald M Dougherty', \\ Rafael M Santos ${ }^{2}$, Ignacio Valdes', Alan C Swann', Ernest S Barratt ${ }^{3}$ and Ponnada A Narayana ${ }^{2}$ \\ 'Department of Psychiatry and Behavioral Sciences, University of Texas Health Science Center Houston, TX, USA; ${ }^{2}$ Department of Radiology, \\ University of Texas Health Science Center Houston, TX, USA; ${ }^{3}$ Psychiatry and Behavioral Sciences, University of Texas Medical Branch, Galveston, \\ TX, USA
}

\begin{abstract}
Brain imaging studies find evidence of prefrontal cortical dysfunction in cocaine-dependent subjects. Similarly, cocaine-dependent subjects have problems with behaviors related to executive function and impulsivity. Since prefrontal cortical axonal tracts cross between hemispheres in the corpus callosum, it is possible that white matter integrity in the corpus callosum could also be diminished in cocainedependent subjects. The purpose of this study was to compare corpus callosum white matter integrity as measured by the fractional anisotropy (FA) on diffusion tensor imaging (DTI) between 18 cocaine-dependent subjects and 18 healthy controls. The Barratt Impulsiveness Scale (BIS-II) and a continuous performance test: the Immediate and Delayed Memory Task (IMT/DMT) were also collected. Results of the DTI showed significantly reduced FA in the genu and rostral body of the anterior corpus callosum in cocainedependent subjects compared to controls. Cocaine-dependent subjects also had significantly higher BIS-II scores, greater impulsive (commission) errors, and reduced ability to discriminate target from catch stimuli (discriminability) on the IMT/DMT. Within cocaine dependent subjects there was a significant negative correlation between FA in the anterior corpus callosum and behavioral laboratory measured impulsivity, and there was a positive correlation between FA and discriminability. The finding that reduced integrity of anterior corpus callosum white matter in cocaine users is related to impaired impulse control and reduced ability to discriminate between target and catch stimuli is consistent with prior theories regarding frontal cortical involvement in impaired inhibitory control in cocainedependent subjects.

Neuropsychopharmacology (2005) 30, 610-617, advance online publication, 22 December 2004; doi:10.1038/sj.npp.13006I7
\end{abstract}

Keywords: diffusion tensor imaging; cocaine dependence; impulsivity; prefrontal cortex; corpus callosum; brain imaging

\section{INTRODUCTION}

One of the most consistent findings of brain imaging studies of cocaine abusers is alteration in frontal cortical structure and function (Volkow and Fowler, 2000). Studies of prefrontal cortical function using Positron Emission Tomography (PET) or Single Photon Emission Tomography (SPECT) show changes in prefrontal cortical blood flow or metabolism in chronic cocaine users after discontinuing cocaine. Acutely after cocaine discontinuation, PET studies find increases in frontal cortical blood flow or metabolism, followed by reductions after several days of abstinence

*Correspondence: Dr FG Moeller, Department of Psychiatry and Behavioral Sciences, University of Texas Health Science Center at Houston, 1300 Moursund, Houston, TX 77030, USA, Tel: 7I3 500 2858, Fax: 713500 2624, E-mail: Frederick.g.moeller@uth.tmc.edu Received 17 August 2004; revised 7 October 2004; accepted 14 October 2004

Online publication: 15 October 2004 at http://www.acnp.org/citations/ Npp02160403433/default.pdf
(Volkow et al, 1991, 1992, 1988). In a study using SPECT and perfusion magnetic resonance imaging (MRI), cocaine users who were abstinent for an average of 11 months showed increased regional cerebral blood flow ( $\mathrm{rCBF}$ ) in frontal white matter, and reductions in $\mathrm{rCBF}$ in the cortex and deep white matter (Ernst et al, 2000). The authors interpreted these findings as possibly due to reactive gliosis in frontal white matter of cocaine users. Other studies using volumetric MRI also support alterations in frontal cortical gray and white matter in cocaine-dependent subjects. O'Neill et al (2001) studied cocaine users who used cocaine alone, and cocaine users who used cocaine and alcohol using quantitative MRI. The results of that study were that cocaine-dependent subjects had less gray and white matter in the prefrontal cortex. Furthermore, the structural white matter deficits seen in cocaine users correlated significantly with duration of cocaine use. Fein et al (2002) examined regional cortical volumes in cocaine-dependent subjects abstinent for 6 weeks, finding that cocaine dependence was associated with reduced prefrontal cortical volume and 
performance impairments in executive function. Franklin et al (2002) also found reductions in gray matter as measured by voxel-based morphometry on structural MRI in ventromedial orbitofrontal, anterior cingulate, insular, and superior temporal cortices of cocaine-dependent subjects in comparison to controls. However, white matter did not differ between the two groups. Bartzokis et al (2002) studied white matter volumes using structural MRI in 37 cocaine-dependent subjects and 52 healthy controls between the ages of 19 and 47 years. Results of that study were that the age-related increase in white matter volume seen in normal controls was not present in cocaine-dependent subjects, suggesting an arrested development of white matter maturation in frontal lobes of cocaine-dependent subjects. Taken together, these studies provide evidence that cocaine-dependent subjects have alterations in prefrontal cortical structure and function, with changes in both gray and white matter.

There is also a growing body of evidence relating cocaine dependence to impairment in impulse control. Several studies found increases in questionnaire-measured impulsivity in cocaine-dependent subjects (Moeller et al, 2002; Patkar et al, 2004). Similarly, recent studies using behavioral laboratory measures of impulsivity also reported increased impulsivity in cocaine-dependent subjects (Coffey et al, 2003; Moeller et al, 2002). Since the prefrontal cortex is one area thought to be important in impulse control (Dalley et al, 2002a, b; Winstanley et al, 2003), it is possible that the increased impulsivity seen in chronic cocaine use is related to changes in prefrontal cortical structure.

Diffusion tensor imaging (DTI) provides information about the microstructural organization of deep tissues in vivo (Taber et al, 2002, 2004). Specifically, DTI provides information about white matter integrity through measurement of directionality of motion of water molecules in the brain. In the absence of barriers, water molecules in tissues undergo Brownian motion along all possible directions. This is referred to as isotropic diffusion. However, in the presence of barriers such as axonal membranes, the diffusion of water molecules exhibits directional preference. This is referred to as anisotropic diffusion. Organized structures such as white matter fiber tracts exhibit a large anisotropy since the water diffusion is restricted along the length of the tracts. A reduction in the anisotropy implies less restraint of water molecules that may be related to subtle white matter pathology and loss of integrity in fiber tracts that are not evident with other radiological modalities, including conventional MRI (Klingberg et al, 2000). The most commonly used index for quantifying the anisotropy is fractional anisotropy (FA) that has been recently shown to be less affected by noise than other measures (Hasan et al, 2004).

There is growing evidence that many psychiatric disorders and substance abuse may involve white matter pathology and impaired cortical communication as a result of compromised fiber connectivity between different brain regions. For example, Pfefferbaum et al (2000) have shown a correlation between FA values in the splenium of the corpus callosum and working memory in chronic alcoholics. These results provide some of the first in vivo evidence of disrupted white matter microstructure in chronic alcoholics. The finding of a relationship between FA values in the splenium of the corpus callosum and performance was replicated in controls by Madden et al (2004) who found a negative correlation between FA and reaction time. Also based on DTI studies, Lim et al (2002) observed compromised white matter integrity in the inferior frontal brain region in cocaine users. This finding of disrupted connectivity in the inferior frontal regions is consistent with the suggested critical role of the prefrontal cortex in impaired decision-making that is evident in cocaine users (Jentsch and Taylor, 1999). Thus, DTI has the potential to provide information about the role of white matter integrity on impulsivity and an objective metric of brain structure that could have important implications in the pathophysiology of cocaine dependence and associated behaviors.

The purpose of this study was to determine whether cocaine-dependent subjects differed from nondrug using controls on white matter integrity using DTI. We further sought to determine whether there were differences between groups on questionnaire and behavioral laboratory measured impulsivity. Finally, we sought to determine whether there was any relationship between white matter integrity and impulsivity in cocaine-dependent subjects.

\section{MATERIALS AND METHODS}

\section{Subjects}

A total of 18 subjects with current cocaine dependence and 18 nondrug using controls were recruited through newspaper advertisements for research volunteers. All subjects were screened for psychiatric and nonpsychiatric medical disorders using the Structured Clinical Interview for DSMIV (SCID) (First et al, 1996), a medical history and physical examination. Subjects also underwent the Addiction Severity Index (McLellan et al, 1992) to document lifetime drug and alcohol use. Cocaine users who did not meet current DSM-IV criteria for cocaine dependence, or who met current criteria for other substance dependence besides cocaine were excluded. Cocaine users were also excluded if they had current or past nonpsychiatric medical disorders which affect the central nervous system (CNS), or had Axis I disorders other than substance abuse or dependence. Healthy controls were excluded if they had any current or past DSM-IV Axis I disorders, nonpsychiatric medical disorders that affect the CNS, or had a positive urine drug screen. Urine drug screening was performed on all subjects using an immunochromatographic assay for THC, opiates, cocaine (benzoylecgonine), and benzodiazepines (Syva Company). All subjects were free of alcohol at the time of testing as determined by an Intoximeter Alcosensor III breathalyzer (Intoximeters, Inc., St Louis MO). This study was approved by the Committee for the Protection of Human Subjects of the University of Texas Health Science Center at Houston, and was performed in accordance with the Declaration of Helsinki. All cocaine-dependent subjects were referred for treatment of cocaine dependence at the end of the study.

\section{Behavioral Measures}

The Barratt Impulsiveness Scale version 11 (BIS-11) (Patton et $a l, 1995)$ is a 30 -item questionnaire which has been 
extensively used in research on impulsivity and impulse control disorders. Previous research found increased scores on the BIS-11 in a number of impulsive populations, including cocaine dependence (Moeller et al, 2002), and Bipolar Disorder (Swann et al, 2001). The BIS-11 has three subscales determined by factor analysis: (1) Motor, or acting without thinking, (2) Attentional, not focusing on the task at hand, and (3) Nonplanning, not thinking carefully (Patton et al, 1995).

The Immediate and Delayed Memory Task (IMT/DMT) (Dougherty et al, 2002) is a continuous performance test in which subjects are presented with a series of five-digit numbers via a computer monitor. Subjects are told to press a mouse button when numbers appear that are identical to the preceding stimulus and withhold a response if the numbers are not identical. The IMT/DMT consists of two parts; the immediate memory task (IMT) in which stimuli appear consecutively, and the delayed memory task (DMT) in which the stimuli are separated by three 'distracter' stimuli that the subjects are told to ignore. The IMT/DMT yields data related to attention, memory, and impulse control including: (1) correct detections or 'hits', which are the percentage of responses to matching stimuli; (2) latency, which is the period of time in milliseconds before a response is made, to either a target (correct) stimulus or a 'catch' stimulus which differs from the target stimulus by only one digit; (3) commission errors, in which the subject responds to a 'catch' stimulus which differs by one digit from the target stimulus; (4) the nonparametric signal detection score $A^{\prime} . A^{\prime}$ is a bias-free measure of discrimination or detectability of signal from noise that is analogous to the signal detection parameter $d^{\prime}$ (Gescheider 1985). Unlike $d^{\prime}, A^{\prime}$ is distribution-free and does not rely on underlying assumptions of normality. $A^{\prime}$ is calculated according to the formula in Donaldson (1992). Scores range from 0.5 (equal to chance) to 1.0 (perfect target/catch discriminability), with higher $A^{\prime}$ values indicating better discrimination.

Commission errors are conceptually related to impulsivity in that the inability to withhold an inappropriate behavioral response is a key aspect of some definitions of impulsivity (Moeller et al, 2001). Supporting this conceptual association is the fact that false alarms have previously been found to be correlated with questionnaire measures of impulsivity (Dougherty et al, 2000), and to be increased in impulsive groups such as adolescents with conduct disorder (Dougherty et al, 2003), and correlate with symptoms of mania in patients with Bipolar Disorder (Swann et al, 2003).

\section{DTI}

Full brain DTI (Basser 1995; Hasan et al, 2002) was acquired with a diffusion sensitized dual spin echo prepared echoplanar imaging (SE-EPI) sequence, (Hasan et al, 2002; Moseley et al, 2002; Bammer, 2003) on a 1.5T General Electric echospeed CNV MRI scanner using a standard quadrature RF Head Coil. The gradient system is capable of producing a maximum gradient amplitude of $40 \mathrm{mT} / \mathrm{m}$ on all channels with a slew rate of $120 \mathrm{~T} / \mathrm{m} / \mathrm{s}$. The dual spin echo sequence has been shown to reduce image distortion associated with residual eddy currents induced by the large diffusion encoding gradient pulses (Reese et al, 2003). The sequence utilizes ramp sampling to minimize distortion and image artefacts. The diffusion weighting factor is set to $1400 \mathrm{~s} / \mathrm{mm}^{2}$ and the diffusion tensor encoding scheme is based on the uniformly distributed and balanced rotationally invariant Icosa21 tensor-encoding set (Hasan et al, 2001a; Hasan and Narayana, 2003). Following the acquisition of sagittal scout images, full brain axial sections were acquired with a $4 \mathrm{~mm}$ slice thickness with no gap, $128 \times 128$ matrix, and a field of view of $24 \times 24 \mathrm{~cm}$. The echo time was $79.3 \mathrm{~ms}$ with a repetition time of $5000 \mathrm{~ms}$ and four averages. This provided an acceptable signal-to-noise ratio $\left(\mathrm{SNR}_{0} \sim 50\right)$ to enable region of interest analysis. The total DTI scanning time was $7.3 \mathrm{~min}$. To increase the image registration fidelity, facilitate white-gray matter classification, and enhance the specificity of region-of-interest analysis (Pfefferbaum and Sullivan, 2003), fast spin echo proton density and $\mathrm{T} 2$-weighted images were acquired from the same location as DTI.

\section{DTI Post Processing}

The magnitude averaged diffusion weighted and encoded MRI images were first spatially filtered using a $3 \times 3$ window median filter. The images were then registered and distortion corrected using the Automated Image Registration (AIR) package (Woods et al, 1998). The distortion corrected images were decoded using a least-squares singular value decomposition approach to estimate the diffusion tensor elements (Hasan et al, 2002). The tensor diagonalization and anisotropy maps were computed based on a thresholded intensity erosion-dilation and positive definite mask and accelerated using the analytical diagonalization approach (Hasan et al, 2001b). The output DTI data were interpolated to attain isotropic voxels and the reformatted data sets were used further to obtain multiplane reports and mpeg movies for visualization, region of interest segmentation, and statistical analysis (Hasan et al, 2001b).

The corpus callosum was the focus of this analysis, based on three factors. First, the corpus callosum is easily and reliably identifiable on DTI images due to the large concentration of white matter fiber tracts. This allows for a clear separation of white matter from gray matter and CSF, which are significant confounding factors in the DTI analysis (Bhagat and Beaulieu, 2004). Second, corpus callosum white matter tracts are significantly influenced by cortical damage (de Lacoste et al, 1985), thus subtle damage to the prefrontal cortex due to cocaine use may be seen in changes in corpus callosum FA. Lastly, studies in subjects with Attention Deficit Hyperactivity Disorder (ADHD) found corpus callosum volumes to be related to impulsivity measures (Giedd et al, 1994). In order to compare regions of the corpus callosum and thereby examine fiber tracts linked to different cortical regions, the corpus callosum was divided into seven segments based on the previous work by Witelson (1989) (see Figure 1).

\section{Statistical Analyses}

Student's $t$-tests were used to examine group differences on continuous demographic variables. The Pearson $\chi^{2}$ analysis was used to compare groups on categorical demographic variables. Pearson correlations were used to examine the 


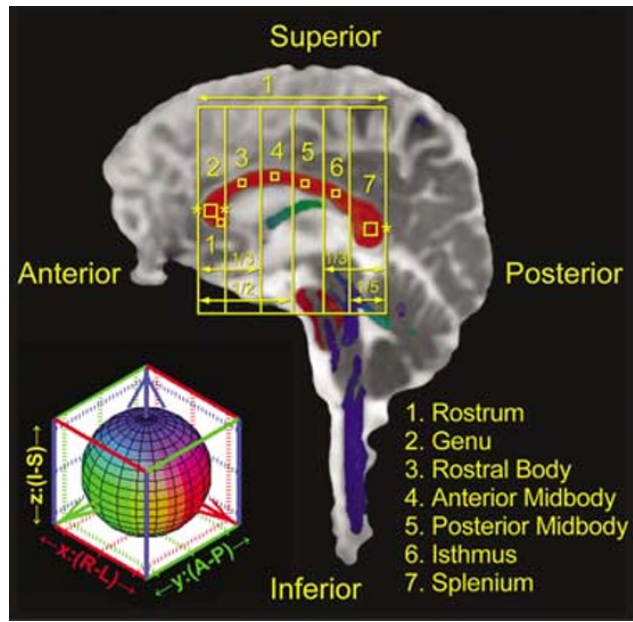

Figure I Division of corpus callosum into regions of interest.

relationship between normally distributed variables, and Spearman correlations were used to examine relationships between non-normally distributed variables. Group comparisons on FA in the seven regions of the corpus callosum were performed using the SPSS ${ }^{\odot}$ Mixed Model analysis of variance (ANOVA), with a first order autoregressive (AR1) model of the covariance structure. The Mixed Model analysis included one within-subjects variable, group with two levels (cocaine dependent $v s$ controls), and one withinsubjects factor, region of the corpus callosum with seven levels based on the seven segments in the previous work by Witelson (1989). Post hoc comparisons of group differences in specific regions of the corpus callosum were performed using the Dunnet-Sidak correction for multiple comparisons. Group comparisons on impulsivity measures were performed using ANOVA.

\section{RESULTS}

\section{Demographics}

A total of 18 cocaine-dependent subjects and 19 controls were recruited and scanned using DTI. One control subject was dropped from the analysis after she was found to have a previously unknown mass in the cerebellum.

Of the 36 subjects included in the statistical analyses, four of the controls were women and 14 were men, identical to the gender distribution of the cocaine-dependent subjects $\left(\chi^{2} p=1.00\right)$. The mean age for the cocaine-dependent subjects was $33.1 \pm 8.7$ years ranging from 20 to 45 years. The mean age of the controls was $30.3 \pm 7.7$ years ranging from 21 to 47 years. This was not a statistically significant difference in age between groups $(t=1.015, \mathrm{df}=34$, $p=0.317)$. Handedness did not differ statistically between groups, with all subjects being right handed with the exception of two left-handed controls and one left-handed cocaine-dependent subject $\left(\chi^{2} p=0.546\right)$.

\section{Drug Use}

Cocaine-dependent subjects reported an average of 3.9 uses of cocaine per week (range $<1-7$ ), spending on average
$\$ 109$ per occasion with a range of $\$ 20-\$ 700$. In total, $67 \%$ of the cocaine-dependent subjects smoked cocaine (crack) and $33 \%$ reported intranasal cocaine use. Cocaine-dependent subjects reported using cocaine for an average of 9.7 \pm 7.1 years ranging from 2 to 28 years. A total of 11 cocainedependent subjects had a positive urine drug screen for cocaine, four were positive for THC and one was positive for opiates at the time of DTI scanning. Two cocainedependent subjects met criteria for past alcohol dependence. All cocaine-dependent subjects had some current or past alcohol use, drinking on average 4.2 days per week. Subjects reported drinking alcohol for an average of $13.9 \pm 6.8$ years, ranging from 3 to 25 years. Six of the 18 cocaine-dependent subjects were polydrug users. These subjects had a history of using two other classes of drugs besides cocaine and marijuana over 50 times. These drugs included amphetamine-methamphetamine-MDMA, benzodiazepines, and hallucinogens. Other drugs used by cocaine-dependent subjects were marijuana (94.4\%), amphetamine-methamphetamine-MDMA (50\%), opiates (38.9\%), benzodiazepines (61.1\%), hallucinogens (38.9\%), and other sedative-hypnotics (16.7\%).

\section{Quantitative Regional DTI}

Mean FA values for cocaine-dependent subjects and controls for each of the seven regions of the corpus callosum are shown in Table 1. There was a significant group effect on $\mathrm{FA}(\mathrm{F}=4.55, \mathrm{df}=1,61.4, p=0.037)$. Post hoc comparisons for the regions of the corpus callosum found a significant group difference in the genu $(\mathrm{F}=7.53$, $\mathrm{df}=1,200.3, p=0.007)$ and rostral body $(\mathrm{F}=8.43, \mathrm{df}=1$, 200.3, $p=0.004$ ), with cocaine-dependent subjects showing reduced FA in both of these regions compared to controls.

\section{Impulsivity Measures}

Mean BIS-11 and commission errors for cocaine-dependent subjects and controls are shown in Table 2. Cocainedependent subjects showed significantly higher BIS-11 total scores $(\mathrm{F}=11.9, \mathrm{df}=1,34, p=0.001)$ as well as motor $(\mathrm{F}=12.6, \mathrm{df}=1,34, p=0.001)$ and nonplanning $(\mathrm{F}=13.4$, $\mathrm{df}=1,34, p=0.001$ ) subscales. However, there was no significant difference in attentional subscale scores $(\mathrm{F}=0.86, \mathrm{df}=1,34, p=0.36)$.

Table I Mean Corpus Callosum Fractional Anisotropy Values ( $\times 1000)$ by Region and Group

\begin{tabular}{lll} 
Region & Cocaine & Control \\
\hline Rostrum & $338 \pm 40$ & $369 \pm 63$ \\
Genu & $533 \pm 48^{\mathrm{a}}$ & $580 \pm 54$ \\
Rostral body & $361 \pm 39^{\mathrm{a}}$ & $415 \pm 62$ \\
Anterior mid-body & $360 \pm 49$ & $374 \pm 57$ \\
Posterior mid-body & $357 \pm 47$ & $376 \pm 60$ \\
Isthmus & $385 \pm 76$ & $361 \pm 51$ \\
Splenium & $560 \pm 46$ & $564 \pm 57$ \\
\hline
\end{tabular}

${ }^{a}$ Areas of significant reduction in cocaine-dependent subjects. 
Table 2 Behavioral Measures by Group

\begin{tabular}{lcc}
\hline Measure & Cocaine dependent & Controls \\
\hline IMT correct detections & $78.6 \pm 11.1 \% \%^{*}$ & $88.7 \pm 6.4 \%$ \\
IMT commission errors & $30.9 \pm 16.5 \% *$ & $20.4 \pm 11.7 \%$ \\
IMT latency for catch trials (ms) & $477.8 \pm 51.9 *$ & $436.4 \pm 60.2$ \\
IMT A' & $0.818 \pm 0.0$ A $^{*}$ & $0.907 \pm 0.04$ \\
DMT correct detections & $82.0 \pm 14.6 \% *$ & $92.1 \pm 6.3 \%$ \\
DMT commission errors & $29.0 \pm 17.4 \% *$ & $16.4 \pm 12.3 \%$ \\
DMT latency for catch trials & $559.7 \pm 108.9$ & $480.2 \pm 212.5$ \\
DMT A' & $0.834 \pm 0.13 *$ & $0.93 \pm 0.06$ \\
BIS-I I nonplanning score & $25.4 \pm 4.7 *$ & $19.9 \pm 4.3$ \\
BIS-I I attentional score & $16.1 \pm 4.4$ & $14.8 \pm 3.9$ \\
BIS-II motor score & $24.7 \pm 4.2 *$ & $20.4 \pm 2.7$ \\
BIS-I I total score & $65.9 \pm 10.6 *$ & $54.1 \pm 10.0$ \\
\hline
\end{tabular}

*Significant group differences.

Cocaine-dependent subjects also had significantly lower correct detections on both the IMT $(\mathrm{F}=11.2, \mathrm{df}=1,34$, $p=0.002)$ and the DMT $(\mathrm{F}=7.3, \mathrm{df}=1,34, p=0.011)$, as well as significantly higher commission errors for the IMT $(\mathrm{F}=4.8, \mathrm{df}=1,34, p=0.035)$ and the DMT $(\mathrm{F}=6.27, \mathrm{df}=1$, $34, p=0.017)$, and a longer response latency for 'catch' stimuli $(\mathrm{F}=4.87, \mathrm{df}=1,34, p=0.034)$. Cocaine-dependent subjects also had significantly lower signal detection as measured by $A^{\prime}$ for both the IMT $(\mathrm{F}=15.7, \mathrm{df}=1,34$, $p=0.000)$ and the DMT $(\mathrm{F}=7.76, \mathrm{df}=1,34, p=0.009)($ see Table 2).

\section{Relationship between Behavioral Measures and DTI}

In order to determine whether there was a relationship between the behavioral measures and the FA values for the two regions of the anterior corpus callosum that were significantly different between the two groups, a Pearson correlation analysis was performed. That analysis demonstrated a significant negative correlation between impulsivity as measured by IMT commission errors and FA in the rostral body of the corpus callosum $(r=-0.421, p=0.011)$, as well as a significant positive correlation between signal detection as measured by IMT $A^{\prime}$ and FA in the rostral body of the corpus callosum $(r=0.469, p=0.004)$ for all subjects. These correlations were primarily due to the cocainedependent subjects since neither the correlation between IMT commission errors and FA $(r=-0.003, p=0.990)$, nor the correlation between IMT $A^{\prime}$ and FA $(r=0.060$, $p=0.814)$ were significant in controls. Both correlations were significant within cocaine-dependent subjects (IMT commission errors and FA $r=-0.708, p=0.001$, IMT $A^{\prime}$ and FA $r=0.541, p=0.020$ ) (see Figures 2 and 3). There were no significant correlations between BIS total scores or subscales and FA values.

\section{Relationship between Regional DTI and Drug Use}

Within cocaine-dependent subjects, there was a significant negative correlation between FA in the genu and years of

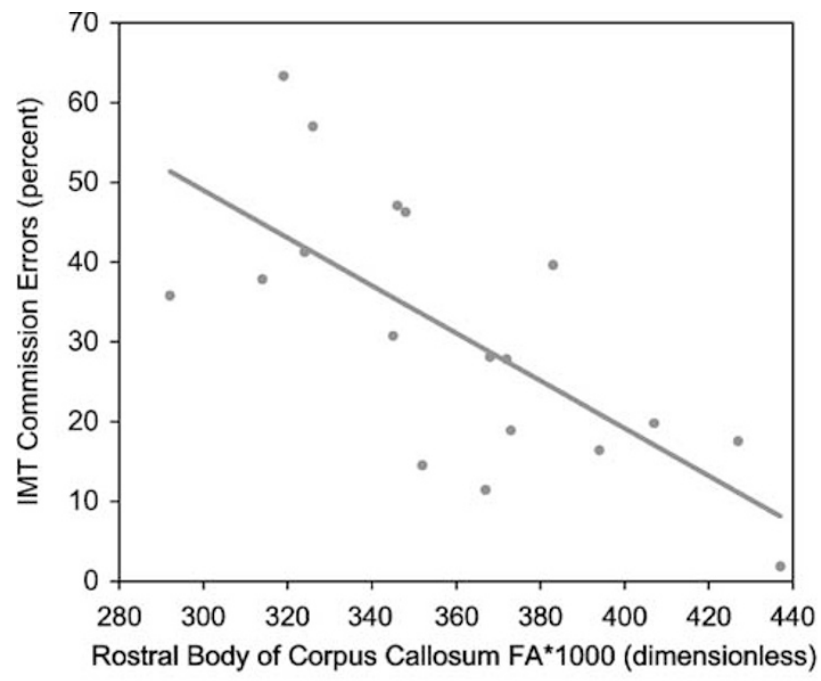

Figure 2 Correlation between behavioral laboratory measured impulsivity and white matter integrity in the rostral body of the corpus callosum within cocaine-dependent subjects.

self-reported cocaine use (Spearman $r=-0.505, p=0.033$ ), and years of alcohol use (Spearman $r=-0.612, p=0.007$ ). However, there was also a significant negative correlation between age and FA $(r=-0.690, p=0.002)$. Since age was positively correlated with years of cocaine (Spearman $r=0.532, p=0.023$ ) and years of alcohol use (Spearman $r=0.681, p=0.002$ ), a partial correlation controlling for age was performed. The results of that correlation were no longer significant for either cocaine (partial correlation $r=-0.276, p=0.28$ ) or for alcohol (partial correlation $r=-0.261, p=0.311)$ after controlling for age. Since the use of amphetamines has been related to changes in brain structure (Cowan et al, 2003), an analysis was carried out to compare cocaine-dependent subjects with a history of use of amphetamines (AMP +$)(n=9)$ to those without this history (AMP-) $(n=9)$. The results of that analysis showed no significant differences between subjects with or without a history of use of amphetamines in either the genu (AMP $+540 \pm 51.2, \mathrm{AMP}-526 \pm 46.8, t=0.59, p=0.56$ ) or rostral body (AMP $+352 \pm 29.8$, AMP $-370 \pm 46.9, t=0.996$, $p=0.334)$ of the corpus callosum.

\section{DISCUSSION}

Although the entire corpus callosum was examined for differences between cocaine-dependent subjects and controls, significant differences were only seen in two regions of the anterior corpus callosum after correction for multiple comparisons. The fact that reduced FA in cocainedependent subjects was limited to the anterior corpus callosum is consistent with prior imaging studies showing changes in prefrontal cortical structure and function in cocaine-dependent subjects (Volkow and Fowler, 2000). A post mortem study showed that the anterior corpus callosum exhibits Wallerian degeneration after injury to the inferior frontal and anterior inferior parietal regions of the brain (de Lacoste et al, 1985). Prior studies have also 


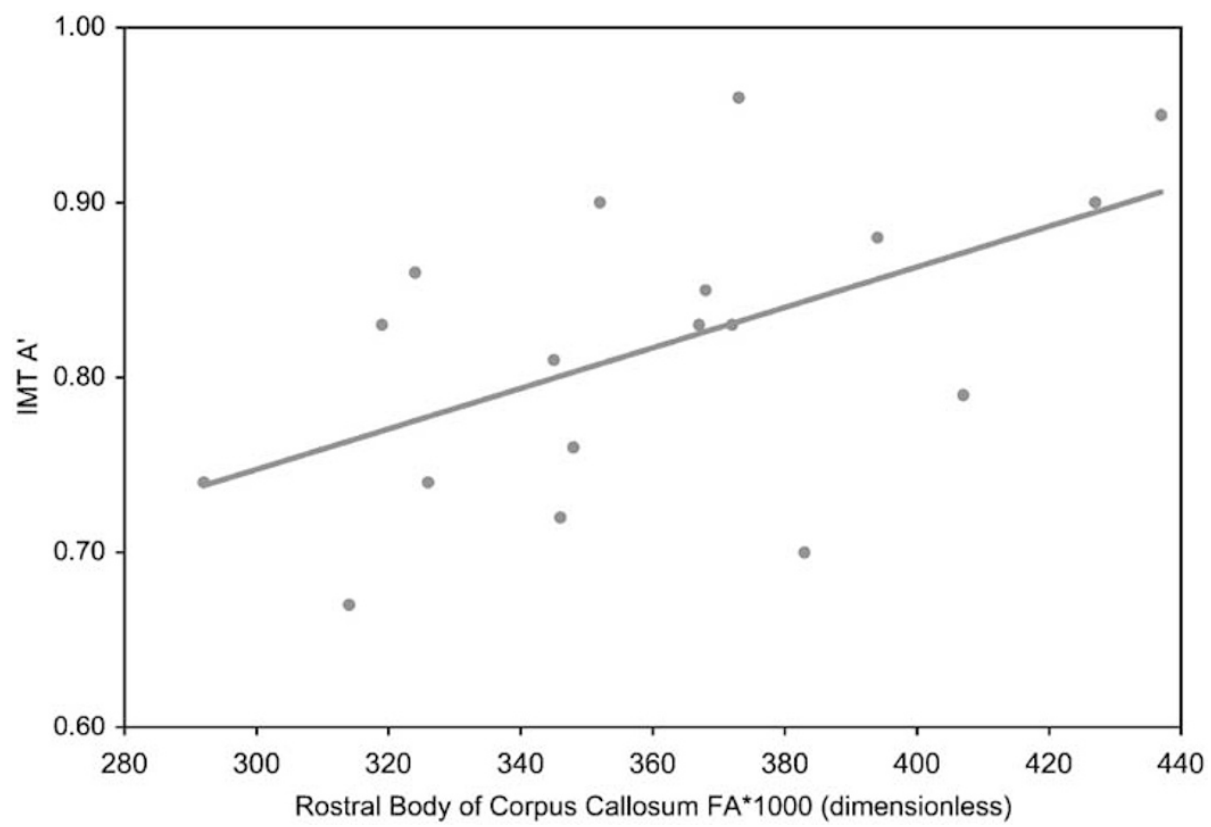

Figure 3 Correlation between discriminability on the IMT and white matter integrity in the rostral body of the corpus callosum within cocaine-dependent subjects.

shown that Wallerian degeneration in white matter tracts secondary to cortical injury can be detected by reductions in FA on DTI (Pierpaoli et al, 2001; Thomalla et al, 2004). Thus, it is possible that the reduced FA seen in the anterior corpus callosum in cocaine-dependent subjects was due to damage to the prefrontal cortex.

Cocaine-dependent subjects also showed greater impulsivity than controls as measured by the BIS-11 and commission errors on the IMT/DMT. Within cocainedependent subjects, those who had the lowest white matter integrity in the anterior corpus callosum had the highest impulsivity and poorest ability to discriminate between target and catch stimuli on the IMT. Unlike one previous study in schizophrenia (Hoptman et al, 2002), there was no correlation in the present study between BIS scores and white matter integrity. The finding of reduced anterior corpus callosum white matter integrity related to impaired impulse control and reduced ability to discriminate between target and catch stimuli in cocaine users is consistent with prior theories regarding frontal cortical circuitry involvement in impaired inhibitory control in cocaine-dependent subjects (Jentsch and Taylor, 1999). Another potential source of the relationship between behavioral measures and reduced FA is reduced function of the corpus callosum itself rather than damage to the prefrontal cortex. Prior studies by Rueckert and Levy (1996) found an association between efficiency of callosal transfer of information using bimanual coordination tasks and sustained attention in children and adults (Rueckert et al, 1999). Thus, it is possible that diminished sustained attention due to reduced communication between the two hemispheres could be responsible for the reduced discriminability and increased commission errors seen in cocaine-dependent subjects.

Direct damage to white matter tracts rather than secondary changes in white matter tracts related to damage to the prefrontal cortex is also consistent with prior studies in substance-dependent groups. As discussed above, several prior studies have found white matter changes in cocainedependent subjects (Bartzokis et al, 2002; Ernst et al, 2000; Lim et al, 2002). Cocaine is known to cause brain damage through cerebral ischemia (Johnson et al, 2001). More subtle changes in white matter could also be due to effects of cocaine on myelin production. A recent study comparing gene expression in the nucleus accumbens of cocaine users to controls found a decrease in cocaine users in several myelin-related genes, including myelin basic protein, proteolipid protein, and myelin-associated oligodendrocyte basic protein (Albertson et al, 2004).

Thus, it is possible based on previous research that the reduced FA seen in cocaine users was due to effects of cocaine. However, even though only two of the subjects in the current study met criteria for past alcohol dependence, since all subjects had some history of past alcohol use, it is also possible that at least part of the group differences in FA could have been related to alcohol use. There is evidence that chronic alcohol use is associated with reduced white matter integrity as shown by a study of alcoholic women which found reduced FA in the corpus callosum compared to control women (Pfefferbaum and Sullivan, 2002). In addition, since six of the cocaine-dependent subjects were polydrug users, it is possible that drug use other than cocaine, or in combination with cocaine, could have accounted for at least part of the finding of reduced white matter integrity in the cocaine-dependent subjects. To provide information about whether amphetamine use alone was responsible for the changes on DTI, a comparison between cocaine-dependent subjects who reported a history of amphetamine use and those who denied a history of amphetamine use was performed. Since there were no significant differences between subjects who reported a history of amphetamine use $(n=9)$ and those who denied this history $(n=9)$, it is unlikely that the differences in DTI 
were solely due to amphetamine use. However, it cannot be ruled out that amphetamine use could have contributed to reductions in FA.

Based on the correlation with years of substance use, there is indirect evidence that the reduction in white matter integrity seen in the present study could have been caused by cocaine or alcohol use. However, it is also possible that these changes could pre-exist in individuals more prone to cocaine use. Although not directly related to DTI, corpus callosal volumes have been shown to differ in groups at risk for development of substance abuse. A prior MRI study in children with ADHD found reductions in anterior corpus callosum area, which was significantly correlated with impulsivity-hyperactivity subscales of both the parent and teacher Conner's Questionnaire (Giedd et al, 1994). Other studies have found reductions in anterior corpus callosum volume in children with ADHD (Hynd et al, 1991), (Baumgardner et al, 1996). However, another larger MRI study did not find smaller corpus callosum volumes in ADHD children (Castellanos et al, 1996), possibly because this study did not control for position of the brain (Giedd et al, 2001). Another recent study found that childhood abuse was associated with a reduction in area on MRI in the anterior midbody of the corpus callosum (Teicher et al, 2004). Thus, factors that could predispose individuals to substance abuse could also be responsible for changes in corpus callosal white matter.

In summary, this study demonstrated a reduction in white matter integrity in the anterior corpus callosum in cocaine-dependent subjects, which was associated with increased behavioral laboratory measured impulsivity and with reduced ability to discriminate between target and catch stimuli in these individuals. Since this region of the corpus callosum is linked to the prefrontal cortex, it is possible that the reduction in FA and impairment in impulse control and discriminability in the cocainedependent subjects are related to prefrontal cortical pathology secondary to cocaine use. Further research is needed on the etiology of these changes and their potential for prevention or treatment.

\section{ACKNOWLEDGEMENTS}

This study was funded by National Institute on Drug Abuse Grants \#R01DA08425, R01DA15345, K02DA0403, and Dreyfus Health Foundation Grants \#GR1152-02 (FGM) and R01MH61927 (JLS).

\section{REFERENCES}

Albertson DN, Pruetz B, Schmidt CJ, Kuhn DM, Kapatos G, Bannon MJ (2004). Gene expression profile of the nucleus accumbens of human cocaine abusers: evidence for dysregulation of myelin. J Neurochem 88: 1211-1219.

Bammer R (2003). Basic principles of diffusion-weighted imaging. Eur J Radiol 45: 169-184.

Bartzokis G, Beckson M, Lu PH, Edwards N, Bridge P, Mintz J (2002). Brain maturation may be arrested in chronic cocaine addicts. Biol Psychiatry 51: 605-611.

Basser PJ (1995). Inferring microstructural features and the physiological state of tissues from diffusion-weighted images. NMR Biomed 8: 333-344.
Baumgardner TL, Singer HS, Denckla MB, Rubin MA, Abrams MT, Colli MJ et al (1996). Corpus callosum morphology in children with Tourette syndrome and attention deficit hyperactivity disorder. Neurology 47: 477-482.

Bhagat YA, Beaulieu C (2004). Diffusion anisotropy in subcortical white matter and cortical gray matter: changes with aging and the role of CSF-suppression. J Magn Reson Imaging 20: 216-227. Castellanos FX, Giedd JN, Marsh WL, Hamburger SD, Vaituzis AC, Dickstein DP et al (1996). Quantitative brain magnetic resonance imaging in attention-deficit hyperactivity disorder. Arch Gen Psychiatry 53: 607-616.

Coffey SF, Gudleski GD, Saladin ME, Brady KT (2003). Impulsivity and rapid discounting of delayed hypothetical rewards in cocainedependent individuals. Exp Clin Psychopharmacol 11: 18-25.

Cowan RL, Lyoo IK, Sung SM, Ahn KH, Kim MJ, Hwang J et al (2003). Reduced cortical gray matter density in human MDMA (Ecstasy) users: a voxel-based morphometry study. Drug Alcohol Depend 72: 225-235.

Dalley JW, Theobald DE, Eagle DM, Passetti F, Robbins TW (2002a). Deficits in impulse control associated with tonicallyelevated serotonergic function in rat prefrontal cortex. Neuropsychopharmacology 26: 716-728.

Dalley JW, Theobald DE, Pereira EA, Li PM, Robbins TW (2002b). Specific abnormalities in serotonin release in the prefrontal cortex of isolation-reared rats measured during behavioural performance of a task assessing visuospatial attention and impulsivity. Psychopharmacology (Berl) 164: 329-340.

de Lacoste MC, Kirkpatrick JB, Ross ED (1985). Topography of the human corpus callosum. J Neuropathol Exp Neurol 44: 578-591.

Donaldson W (1992). Measuring recognition memory. J Exp Psychol: Gen 121: 275-277.

Dougherty DM, Bjork JM, Harper RA, Marsh DM, Moeller FG, Mathias CW et al (2003). Behavioral impulsivity paradigms: a comparison in hospitalized adolescents with disruptive behavior disorders. J Child Psychol Psychiatry 44: 1145-1157.

Dougherty DM, Bjork JM, Marsh DM, Moeller FG (2000). A comparison between adults with conduct disorder and normal controls on a continuous performance test: differences in response characteristics. Psychol Rec 50: 203-219.

Dougherty DM, Marsh DM, Mathias CW (2002). Immediate and delayed memory tasks: a computerized behavioral measure of memory, attention, and impulsivity. Behav Res Methods Instrum Comput 34: 391-398.

Ernst T, Chang L, Oropilla G, Gustavson A, Speck O (2000). Cerebral perfusion abnormalities in abstinent cocaine abusers: a perfusion MRI and SPECT study. Psychiatry Res 99: 63-74.

Fein G, Di SV, Meyerhoff DJ (2002). Prefrontal cortical volume reduction associated with frontal cortex function deficit in 6week abstinent crack-cocaine dependent men. Drug Alcohol Depend 68: 87-93.

First MB, Spitzer RL, Gibbon M, Williams JBW (1996). Structured Clinical Interview for DSM-IV Axis I Disorders-Patient Edition (SCID-I/P, Version 2.0), Biometrics Research Department, New York State Psychiatric Institute: New York.

Franklin TR, Acton PD, Maldjian JA, Gray JD, Croft JR, Dackis CA et al (2002). Decreased gray matter concentration in the insular, orbitofrontal, cingulate, and temporal cortices of cocaine patients. Biol Psychiatry 51: 134-142.

Gescheider GA (1985). The theory of signal detection. In Gescheider GA (ed). Psychometric Methods, Theory and Application, 2nd edn. Lawrence Erlbaum Associates: Hillsdale, New Jersey.

Giedd JN, Blumenthal J, Molloy E, Castellanos FX (2001). Brain imaging of attention deficit/hyperactivity disorder. Ann NY Acad Sci 931: 33-49.

Giedd JN, Castellanos FX, Casey BJ, Kozuch P, King AC, Hamburger SD et al (1994). Quantitative morphology of the corpus callosum in attention deficit hyperactivity disorder. $\mathrm{Am} J$ Psychiatry 151: 665-669. 
Hasan KM, Alexander AL, Narayana PA (2004). Does fractional anisotropy have better noise immunity characteristics than relative anisotropy in diffusion tensor MRI? An analytical approach. Magn Reson Med 51: 413-417.

Hasan KM, Basser PJ, Parker DL, Alexander AL (2001a). Analytical computation of the eigenvalues and eigenvectors in DT-MRI. J Magn Reson Imaging 152: 41-47.

Hasan KM, Narayana PA (2003). Computation of the fractional anisotropy and mean diffusivity maps without tensor decoding and diagonalization: theoretical analysis and validation. Magn Reson Med 50: 589-598.

Hasan KM, Parker DL, Alexander AL (2001b). Comparison of gradient encoding schemes for diffusion-tensor MRI. J Magn Reson Imaging 13: 769-780.

Hasan KM, Parker DL, Alexander AL (2002). Magnetic resonance water self-diffusion tensor encoding optimization methods for full brain acquisition. Image Anal Stereol 21: 87-96.

Hoptman MJ, Volavka J, Johnson G, Weiss E, Bilder RM, Lim KO (2002). Frontal white matter microstructure, aggression, and impulsivity in men with schizophrenia: a preliminary study. Biol Psychiatry 52: 9-14.

Hynd GW, Semrud-Clikeman M, Lorys AR, Novey ES, Eliopulos D, Lyytinen H (1991). Corpus callosum morphology in attention deficit-hyperactivity disorder: morphometric analysis of MRI. J Learn Disabil 24: 141-146.

Jentsch JD, Taylor JR (1999). Impulsivity resulting from frontostriatal dysfunction in drug abuse: implications for the control of behavior by reward-related stimuli. Psychopharmacology (Berl) 146: 373-390.

Johnson BA, Devous Sr MD, Ruiz P, Ait-Daoud N (2001). Treatment advances for cocaine-induced ischemic stroke: focus on dihydropyridine-class calcium channel antagonists. Am J Psychiatry 158: 1191-1198.

Klingberg T, Hedehus M, Temple E, Salz T, Gabrieli JD, Moseley ME et al (2000). Microstructure of temporo-parietal white matter as a basis for reading ability: evidence from diffusion tensor magnetic resonance imaging. Neuron 25: 493-500.

Lim KO, Choi SJ, Pomara N, Wolkin A, Rotrosen JP (2002). Reduced frontal white matter integrity in cocaine dependence: a controlled diffusion tensor imaging study. Biol Psychiatry 51: 890-895.

Madden DJ, Whiting WL, Huettel SA, White LE, MacFall JR, Provenzale JM (2004). Diffusion tensor imaging of adult age differences in cerebral white matter: relation to response time. Neuroimage 21: 1174-1181.

McLellan AT, Kushner H, Metzger D, Peters R, Smith I, Grissom G et al (1992). The Fifth Edition of the Addiction Severity Index. J Subst Abuse Treat 9: 199-213.

Moeller FG, Barratt ES, Dougherty DM, Schmitz JM, Swann AC (2001). Psychiatric aspects of impulsivity. Am J Psychiatry 158: 1783-1793.

Moeller FG, Dougherty DM, Barratt ES, Oderinde V, Mathias CW, Harper RA et al (2002). Increased impulsivity in cocaine dependent subjects independent of antisocial personality disorder and aggression. Drug Alcohol Depend 68: 105-111.

Moseley M, Bammer R, Illes J (2002). Diffusion-tensor imaging of cognitive performance. Brain Cogn 50: 396-413.

O'Neill J, Cardenas VA, Meyerhoff DJ (2001). Separate and interactive effects of cocaine and alcohol dependence on brain structures and metabolites: quantitative MRI and proton MR spectroscopic imaging. Addict Biol 6: 347-361.

Patkar AA, Murray HW, Mannelli P, Gottheil E, Weinstein SP, Vergare MJ (2004). Pre-treatment measures of impulsivity, aggression and sensation seeking are associated with treatment outcome for African-American cocaine-dependent patients. J Addict Dis 23: 109-122.
Patton JH, Stanford MS, Barratt ES (1995). Factor structure of the Barratt impulsiveness scale. J Clin Psychol 51: 768-774.

Pfefferbaum A, Sullivan EV (2002). Microstructural but not macrostructural disruption of white matter in women with chronic alcoholism. Neuroimage 15: 708-718.

Pfefferbaum A, Sullivan EV (2003). Increased brain white matter diffusivity in normal adult aging: relationship to anisotropy and partial voluming. Magn Reson Med 49: 953-961.

Pfefferbaum A, Sullivan EV, Hedehus M, Adalsteinsson E, Lim KO, Moseley M (2000). In vivo detection and functional correlates of white matter microstructural disruption in chronic alcoholism. Alcohol Clin Exp Res 24: 1214-1221.

Pierpaoli C, Barnett A, Pajevic S, Chen R, Penix LR, Virta A et al (2001). Water diffusion changes in Wallerian degeneration and their dependence on white matter architecture. Neuroimage 13: 1174-1185.

Reese TG, Heid O, Weisskoff RM, Wedeen VJ (2003). Reduction of eddy-current-induced distortion in diffusion MRI using a twicerefocused spin echo. Magn Reson Med 49: 177-182.

Rueckert L, Baboorian D, Stavropoulos K, Yasutake C (1999). Individual differences in callosal efficiency: correlation with attention. Brain Cogn 41: 390-410.

Rueckert L, Levy J (1996). Further evidence that the callosum is involved in sustaining attention. Neuropsychologia 34: 927-935.

Swann AC, Anderson JC, Dougherty DM, Moeller FG (2001). Measurement of inter-episode impulsivity in bipolar disorder. Psychiatry Res 101: 195-197.

Swann AC, Pazzaglia P, Nicholls A, Dougherty DM, Moeller FG (2003). Impulsivity and phase of illness in bipolar disorder. J Affect Disord 73: 105-111.

Taber KH, Pierpaoli C, Rose SE, Rugg-Gunn FJ, Chalk JB, Jones DK et al (2002). The future for diffusion tensor imaging in neuropsychiatry. J Neuropsychiatry Clin Neurosci 14: 1-5.

Taylor WD, Hsu E, Krishnan KR, MacFall JR (2004). Diffusion tensor imaging: background, potential, and utility in psychiatric research. Biol Psychiatry 55: 201-207.

Teicher MH, Dumont NL, Ito Y, Vaituzis C, Giedd JN, Andersen SL (2004). Childhood neglect is associated with reduced corpus callosum area. Biol Psychiatry 56: 80-85.

Thomalla G, Glauche V, Koch MA, Beaulieu C, Weiller C, Rother J (2004). Diffusion tensor imaging detects early Wallerian degeneration of the pyramidal tract after ischemic stroke. Neuroimage 22: 1767-1774.

Volkow ND, Fowler JS (2000). Addiction, a disease of compulsion and drive: involvement of the orbitofrontal cortex. Cereb Cortex 10: $318-325$.

Volkow ND, Fowler JS, Wolf AP, Hitzemann R, Dewey S, Bendriem $B$ et al (1991). Changes in brain glucose metabolism in cocaine dependence and withdrawal. Am J Psychiatry 148: 621-626.

Volkow ND, Hitzemann R, Wang GJ, Fowler JS, Wolf AP, Dewey SL et al (1992). Long-term frontal brain metabolic changes in cocaine abusers. Synapse 11: 184-190.

Volkow ND, Mullani N, Gould KL, Adler S, Krajewski K (1988). Cerebral blood flow in chronic cocaine users: a study with positron emission tomography. Br J Psychiatry 152: 641-648.

Winstanley CA, Chudasama Y, Dalley JW, Theobald DE, Glennon JC, Robbins TW (2003). Intra-prefrontal 8-OH-DPAT and M100907 improve visuospatial attention and decrease impulsivity on the five-choice serial reaction time task in rats. Psychopharmacology (Berl) 167: 304-314.

Witelson SF (1989). Hand and sex differences in the isthmus and genu of the human corpus callosum. A postmortem morphological study. Brain 112: 799-835.

Woods RP, Grafton ST, Holmes CJ, Cherry SR, Mazziotta JC (1998). Automated image registration: I. General methods and intrasubject, intramodality validation. J Comput Assist Tomogr 22: 139-152. 